\title{
Costs from a healthcare and societal perspective among cancer patients after total laryngectomy: are they related to patient activation?
}

\author{
Femke Jansen $^{1}$ • Veerle M. H. Coupé ${ }^{2}$ - Simone E. J. Eerenstein ${ }^{1}$ • C. René Leemans ${ }^{1}$. \\ Irma M. Verdonck-de Leeuw ${ }^{1,3}$
}

Received: 18 July 2017 / Accepted: 23 October 2017 / Published online: 3 November 2017

(C) The Author(s) 2017. This article is an open access publication

\begin{abstract}
Purpose The aim of this study is to investigate the associations between patient activation and total costs in cancer patients treated with total laryngectomy (TL).

Methods All members of the Dutch Patients' Association for Laryngectomees were asked to participate in this crosssectional study. TL patients who wanted to participate were asked to complete a survey. Costs were measured using the medical consumption and productivity cost questionnaire and patient activation using the Patient Activation Measure (PAM). Sociodemographic and clinical characteristics were self-reported, and health status measured using the EQ-5D. The difference in total costs from a healthcare and societal perspective among four groups with different PAM levels were compared using (multiple) regression analyses (5000 bootstrap replications).

Results In total, 248 TL patients participated. Patients with a higher (better) PAM (levels 2, 3, and 4) had a probability of 70,80 , and $93 \%$ that total costs from a healthcare perspective were lower than in patients with the lowest PAM level (difference $€-375$ to $€-936$ ). From a societal perspective, this was
\end{abstract}

Irma M. Verdonck-de Leeuw

IM.Verdonck@vumc.nl

1 Department of Otolaryngology-Head and Neck Surgery, Cancer Center Amsterdam (CCA), VU University Medical Center, PO Box 7057, 1007 MB Amsterdam, The Netherlands

2 Department of Epidemiology and Biostatistics, VU University Medical Center, PO Box 7057, 1007

MB Amsterdam, The Netherlands

3 Department of Clinical Psychology, Faculty Behavioural and Movement Sciences, Amsterdam Public Health Research Institute, Vrije Universiteit Amsterdam, Van der Boechorststraat 1, 1081 BT Amsterdam, The Netherlands
73,87 , and $82 \%$ (difference $€-468$ to $€-719$ ). After adjustment for time since TL, education, and sex, the probability that total costs were lower in patients with a higher PAM level compared to patients with the lowest PAM level changed to $62-91 \%$ (healthcare) and 63-92\% (societal). After additional adjustment for health status, the probability to be less costly changed to $35-71 \%$ (healthcare) and $31-48 \%$ (societal).

Conclusions A better patient activation is likely to be associated with lower total costs from a healthcare and societal perspective.

Keywords Head and neck cancer · Laryngeal cancer . Patient activation - Self-management · Total laryngectomy . Health service utilization

\section{Introduction}

Current healthcare systems increasingly focus on the ability of cancer patients to manage and cope themselves with the consequences of being treated for cancer, defined as selfmanagement [1-4]. Several self-management interventions, including eHealth interventions, have been developed to guide cancer patients in their self-management [2, 5-13]. It has been hypothesized that self-management may improve patients' health outcomes and reduce (healthcare) costs [4, 14].

A previous systematic review of Panagioti et al. [15] indeed found that self-management interventions for different populations with chronic illnesses may reduce healthcare utilization without compromising patients' health outcomes. In cancer patients specifically, only few studies focused on the impact of self-management interventions on (healthcare) costs so far, although several researchers are planning to [8-10]. A recent study comparing psychologist-led care with a nurseled self-management intervention in distressed cancer patients 
showed no evidence for cost-effectiveness of the selfmanagement intervention [12]. However, a stepped care program targeting psychological distress in cancer patients consisting of four steps, including a self-help intervention, was found to be more effective and highly likely to be less costly compared to usual care $[13,16]$.

Although previous studies thus indicated that selfmanagement interventions have the potential to be costeffective or even cost saving, the pathway via which selfmanagement may influence costs is still partly unknown. A recent study by Howell et al. [7] provided a conceptual framework to assess performance of self-management education support in clinical practice. This framework conceptualizes that self-management interventions influence patients' acquired skills, such as self-efficacy, problem-solving skills, and self-monitoring behavior, which in turn may influence patients' confidence to manage (e.g., manage symptoms, emotional impact of illness, and role and relationship changes). Patients' acquired skills as well as patients' confidence to manage may consequently influence patient outcomes, such as improved health status, health-related quality of life (HRQOL), and lower healthcare use and costs.

Previous studies in non-cancer populations indeed found that patients' knowledge, confidence, and ability to manage the disease, defined as patient activation [17], may influence healthcare usage and costs [18-26]. It was generally found that patients with better patient activation levels used preventive care (e.g., mammography screening, care for feet and eyes, or low density lipid-protein cholesterol testing in diabetes patients) more often than less activated patients [18-22], while other forms of healthcare use (e.g., hospitalization) was reduced [18, 20, 22-25]. In addition, activated patients had lower total healthcare costs than less activated patients $[18$, 26]. This suggests that although activated patients may use preventive healthcare more often, total healthcare costs of these activated patients are lower, because they use other (and potentially more expensive) types of healthcare less often. However, these studies did not take costs from a societal perspective into account. Also, no such studies have yet been performed among cancer patients.

Therefore, this study aimed to investigate the associations between patient activation and total costs in cancer patients from both a healthcare and societal perspective. To answer this research question, we studied patients with laryngeal or hypopharyngeal cancer treated with total laryngectomy (TL). As a consequence of TL, several body functions including breathing, smell, swallowing, and voice production are changed [27-30]. In addition, many TL patients experience head, neck, and shoulder mobility problems as well as more generic cancer-related problems such as fatigue, anxiety, and depression [28, 29, 31]. As a results of these problems and changes in body functions, TL patients are expected to report high healthcare and societal costs, even a long time after treatment, as was also reported in a previous study among laryngeal cancer patients in general [32,33]. We hypothesized that TL patients with a better patient activation level report lower costs from both a healthcare and a societal perspective, compared to patients with lower levels of patient activation.

\section{Patients and methods}

\section{Design and study population}

All members $(n=914)$ of the Dutch Patients' Association for Laryngectomees were asked to participate in a cross-sectional study in November 2014 by regular post. Patients who wanted to participate were asked to complete a survey at home comprising of validated questionnaires on healthcare utilization, productivity losses, patient activation, and health status, and study-specific sociodemographic and clinical questions. Patients were included when they were treated with TL, were older than 18 years, and completed the survey. The study was performed in accordance with the Dutch Medical Research Involving Human Subjects Act. Ethical approval was not necessary, as patients were not subjected to procedures or required to follow rules of behavior.

\section{Measures}

Direct medical healthcare utilization, direct non-medical service utilization, and productivity losses in the previous 3 months were measured using the medical consumption questionnaire (iMCQ) [34] and productivity cost questionnaire (iPCQ) [35] developed by the Institute for Medical Technology Assessment (iMTA) of the Erasmus University Rotterdam, the Netherlands. The questionnaire was slightly adapted for usage in this population of TL patients. Direct medical costs in the previous 3 months were calculated by multiplying resource use by the integral cost price [36]. All prices were converted to 2014 prices using the consumer price index. Productivity losses from paid work were calculated by multiplying productivity losses by gender and age-specific costs [36] using the friction cost approach. Thus, productivity losses were only included if start date of absence from work was less than the friction period of 160 days before completion of the questionnaire.

The Patient Activation Measure (PAM) was used to measure patient activation. Patient activation has been defined by Hibbard et al. [37] and consists of four important stages, namely (1) believing that their role in health is important, (2) having confidence and knowledge to take action, (3) actually taking action to improve and maintain one's health, and (4) taking action even under stress. The PAM consists of 13 statements related to these four stages (e.g., "I am confident that I can take actions that will help prevent or minimize some symptoms or problems associated with my health condition") 
[17]. Patients can answer that they 1. strongly disagree, 2. disagree, 3 . agree, or 4 . strongly agree with the statement, or can indicate that the statement is not applicable. A total score is calculated by summing scores of all applicable items and transforming it to a standardized activation score of 0 (low patient activation) to 100 (high patient activation). In this study, a total score was calculated when at least 10 items were completed with a valid score. Patients' total score is categorized into four levels: PAM 1 (score $\leq 47.0$ ), PAM 2 (score between 47.1 and 55.1), PAM 3 (score between 55.2 and 67.0), and PAM 4 (score > 67.0).

In addition, each patient's health status was measured using the EuroQol-5 dimensions (EQ-5D). The EQ-5D consists of five items measuring problems on five domains, namely mobility, self-care, usual activities, pain/discomfort, and anxiety/ depression. Patients are asked to report their level of problems on each of these domains: no problems, some problems, or extreme problems [38]. The resulting profile of answers can be transformed to a value given by the Dutch general public using the EQ-5D index [39]. Also, sociodemographic and clinical characteristics were measured, namely age, sex, living situation, having children, education level, work situation, smoking, drinking, time since TL surgery, treatment with (chemo)radiation, and current speech method.

\section{Statistical analyses}

Statistical analyses were conducted using the IBM Statistical Package for the Social Science (SPSS) version 22 (IBM Corp., Armonk, NY, USA) and STATA version 12.1. Descriptive statistics were used to provide insight into sociodemographic characteristics, clinical characteristics and direct medical healthcare utilization, direct non-medical service utilization, and productivity losses. Chi-squared tests, Fisher's exact tests, independent samples $t$ tests, and MannWhitney tests were used to compare sociodemographic and clinical characteristics among TL patients. Chi-squared tests were used for the variables gender, having children, living arrangement, education level, employment status, smoking status, drinking status, received other treatment, current speech: voice prosthesis, and current speech: injection method. Fisher's exact tests were used for current speech: electrolarynx and current speech: other. Independent samples $t$ tests was used for age, and Mann-Whitney tests were used for years since TL and EQ-5D health status. A $p$ value $<.05$ was considered statistically significant.

To investigate the association between patient activation and total costs from a healthcare and societal perspective, mean costs of the four PAM groups were compared using both unadjusted and adjusted analyses. All analyses were performed using (multiple) regression analyses with dummy coding for PAM level. The analyses were performed twice, once with total costs from a healthcare perspective and once with total costs from a societal perspective (including direct medical, direct non-medical, and productivity losses) as dependent variable. In the adjusted analyses, analyses were adjusted for variables that differed among the PAM groups (education level) and for variables found to have a major univariate influence (a change of $\geq 20 \%$ ) on incremental costs. Variables which were assessed for eligibility were age (continuous), sex (male/female), having children (yes/no), living alone (yes/no), employment status (employed vs. not employed or retired), smoking status (no vs. yes or quitted smoking), drinking status (no vs. yes or quitted drinking), time since total laryngectomy (continuous), additional treatment with (chemo)radiation (no additional treatment vs. (chemo)radiation), and having a voice prosthesis (yes/no).

Besides the abovementioned analyses, an additional multiple regression analysis was performed in which we adjusted for EQ-5D health status (in addition to the other variables included in the second analysis). We adjusted for EQ-5D health status in a separate analysis since patient activation and EQ-5D health status/HRQOL are likely to be strongly associated [40], and both may be associated with total costs.

Since cost data is usually characterized by its non-normal distribution and high variance, studies are seldom powered to detect significant differences in costs among groups. Therefore, as is currently state of the art in economic evaluations, a probabilistic approach was used rather than reliance upon significance levels to investigate the association between PAM level and total costs [41]. The probability that groups with a higher PAM level (levels 2, 3, and 4) had lower costs compared to the group with the lowest PAM level (level 1) was assessed by replicating the regression analyses using biascorrected accelerated bootstrapping with 5000 replications.

\section{Results}

In total, 288 of the 914 (32\%) approached patients actually participated. In this study, only those patients $(n=248)$ were included for whom PAM data and data on direct medical healthcare utilization, direct non-medical service utilization, and productivity losses were available. There were some significant differences between the included $(n=248)$ and the excluded patients $(n=40)$ (Table 1$)$. Included patients were significantly younger (mean $=70$ years, standard deviation $(\mathrm{SD})=9$ versus mean $=73$ years, $\mathrm{SD}=10 ; p=.043)$ and had a significantly shorter time since TL (median $=6$ years, range $0-34$ versus median $=11$ years, range $0-37 ; p=.025$ ).

Of the 248 patients, the mean PAM score was $59(\mathrm{SD}=17)$. Most patients $(n=104)$ had a PAM score between 55.2 and 67.0 (PAM level 3), 56 patients had a low PAM score (PAM level 1), 43 patients had a somewhat higher PAM score (PAM level 2), and 45 patients were in the group with the highest PAM score (PAM level 4). There were no significant 


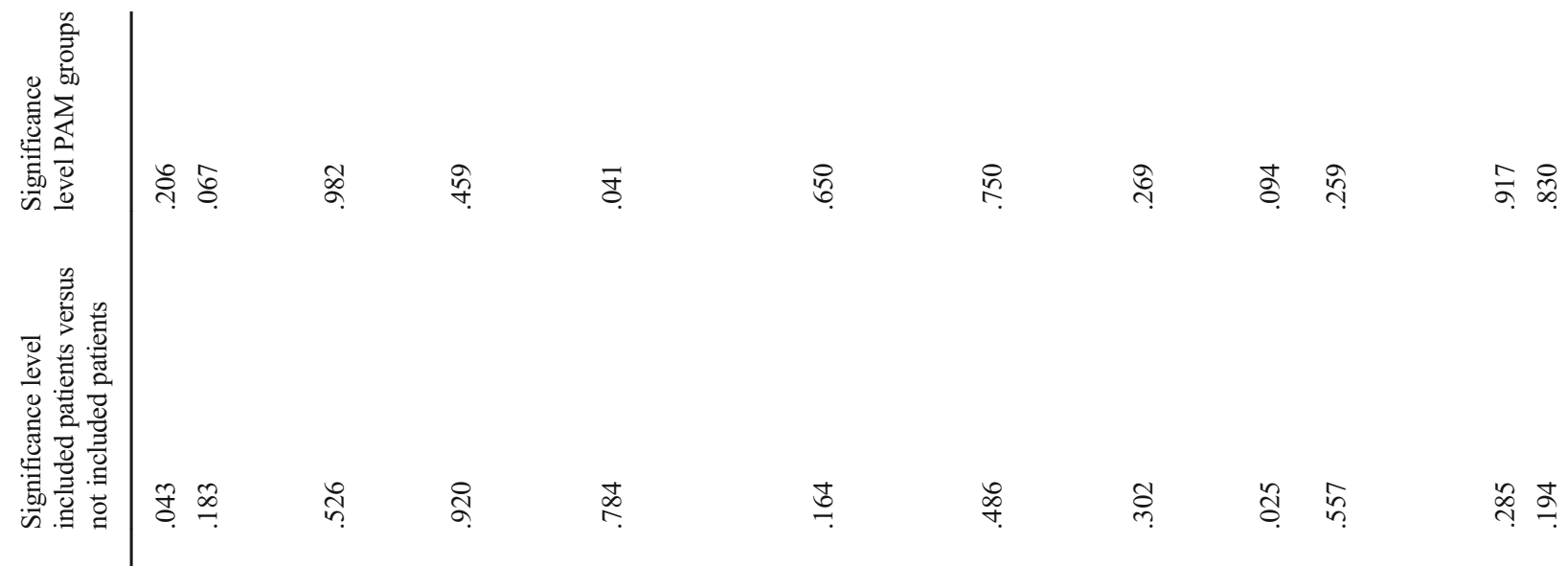

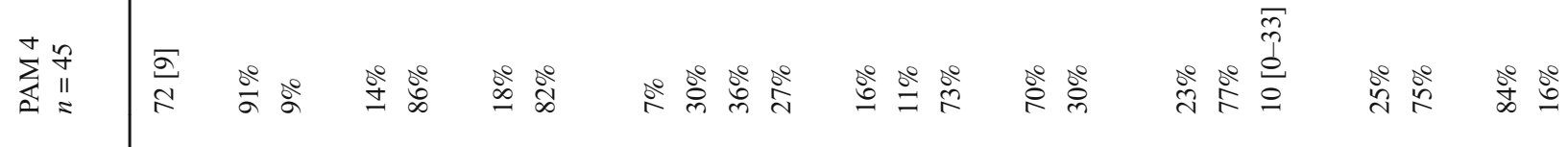

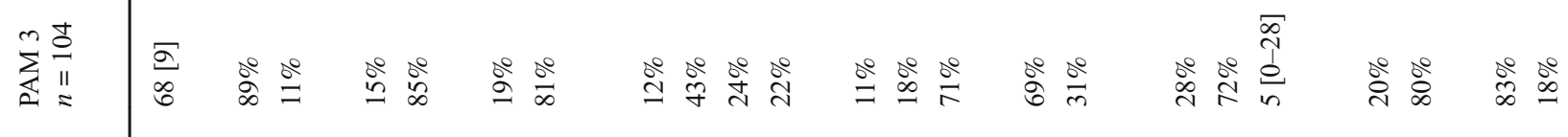

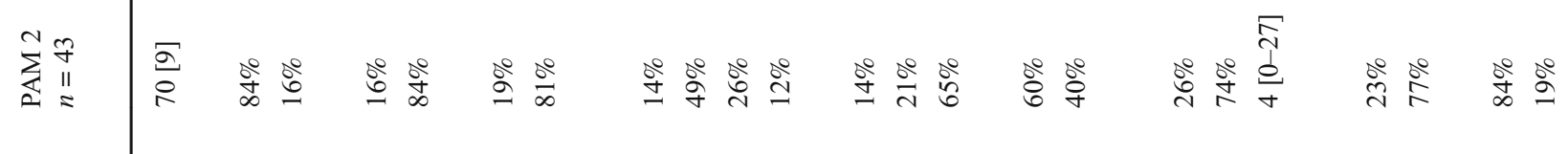

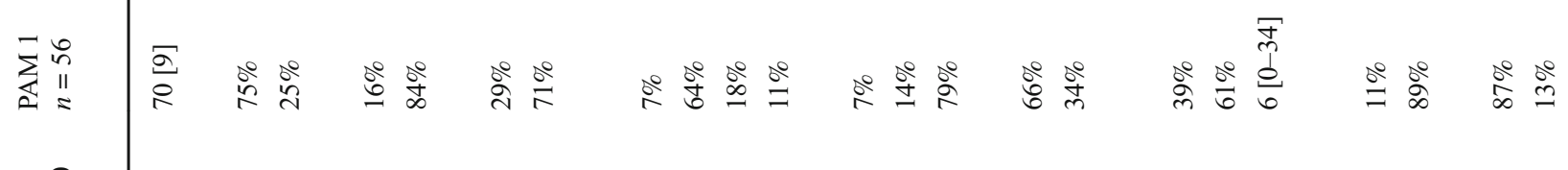

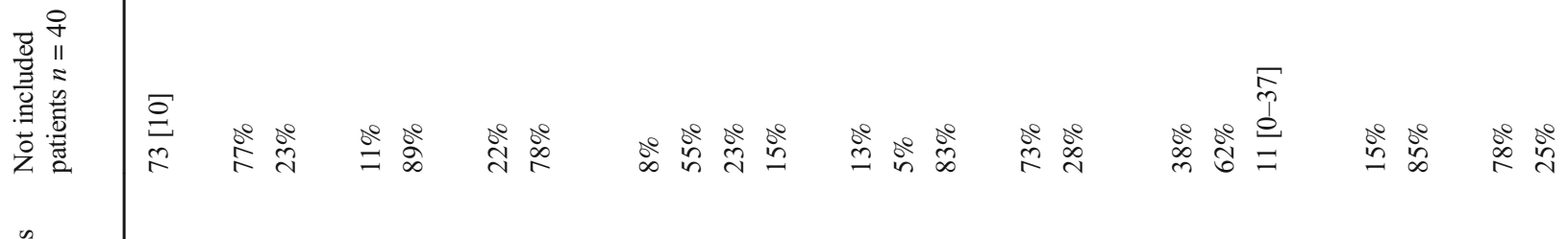

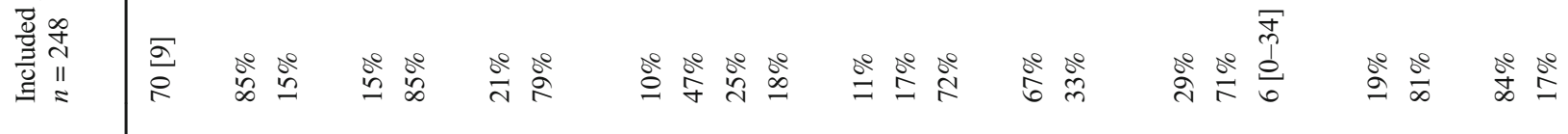

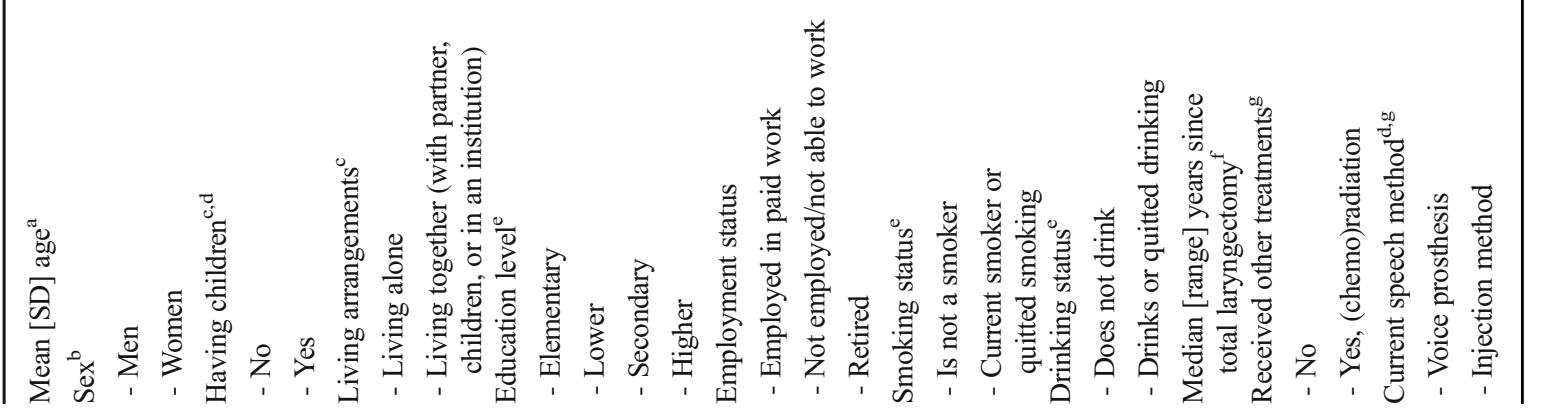




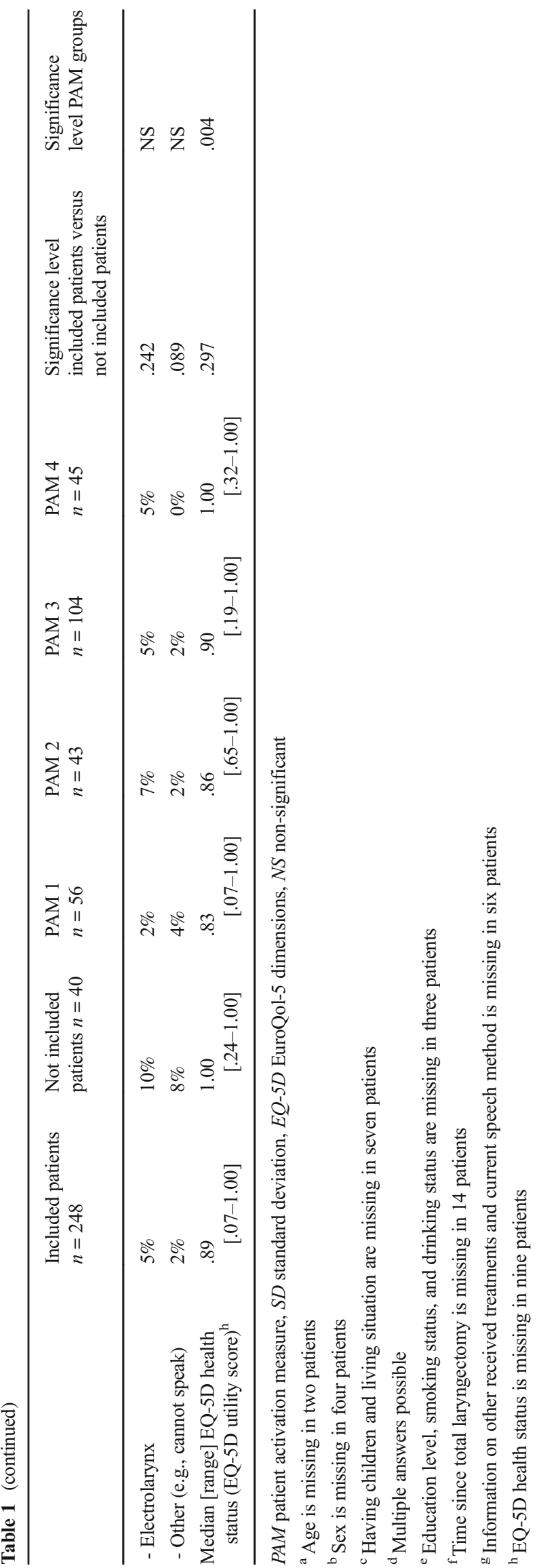

differences between these four groups regarding sociodemographic and clinical characteristics, except for education level $(p=.041)$ and EQ-5D health status $(p=.004)$ (Table 1). The group with the highest PAM level had on average the highest percentage of higher educated patients as well as the highest EQ-5D health status, while the group with the lowest PAM level had the lowest.

\section{Direct medical healthcare utilization, direct non-medical service utilization, and productivity losses}

Results of direct medical healthcare utilization, direct nonmedical service utilization, and productivity losses in the previous 3 months among TL patients are presented in Table 2. In general, more than half of all TL patients visited their general practitioner in the past 3 months (54\%). In addition, 55\% of patients reported that they visited a specialist in an academic center, while $42 \%$ visited a specialist in a general practice. A quarter of all TL patients received care from a physiotherapist, $18 \%$ received care from a speech pathologist, $17 \%$ from an oral hygienist and $14 \%$ from a dietitian. Only $3 \%$ received care from a social worker, $2 \%$ received psychologic or psychiatric help in a private practice and $1 \%$ received psychologic or psychiatric help in a mental healthcare center. About one out of $10 \mathrm{TL}$ patients $(11 \%)$ were admitted to a hospital in the previous 3 months, while $26 \%$ received day treatment. Several TL patients received personal care $(6 \%)$, nursing care $(6 \%)$, or home care (8\%) by a professional. Also, $15 \%$ of the TL patients reported to receive informal care. Two percent of all TL patients reported to have productivity losses, which is $18 \%$ of the employed TL patients.

\section{Patient activation in relation to total costs from a healthcare and societal perspective}

Total costs from a healthcare perspective in the previous 3 months ranged from $€ 1346$ ( $\mathrm{SD}=2597$ ) in the group with the highest PAM level to $€ 2282(\mathrm{SD}=3798)$ in the group with the lowest PAM level (Table 3). Total costs from a societal perspective ranged from $€ 1909(\mathrm{SD}=3855)$ in the group with the highest PAM level to $€ 2627$ ( $S D=4147$ ) in the group with the lowest PAM level. In the unadjusted analysis, patients in the group with the highest PAM level had a 93\% probability that total costs from a healthcare perspective were lower than costs in the group with the lowest PAM level (Tables 3 and 4). This probability was $82 \%$ for total costs from a societal perspective. For the other two groups, probabilities of respectively 80 and $87 \%$ (PAM 3 vs. PAM 1) and 70 and $73 \%$ (PAM 2 vs. PAM 1) were found. After adjusting for potential confounders (time since TL, sex, and education level), these probabilities changed to respectively 91 and $79 \%$ (PAM 4 vs. PAM 1), 88 and 92\% (PAM 3 vs. PAM 1), and 62 and $63 \%$ (PAM 2 vs. PAM 1). After adjusting for potential confounders and EQ- 


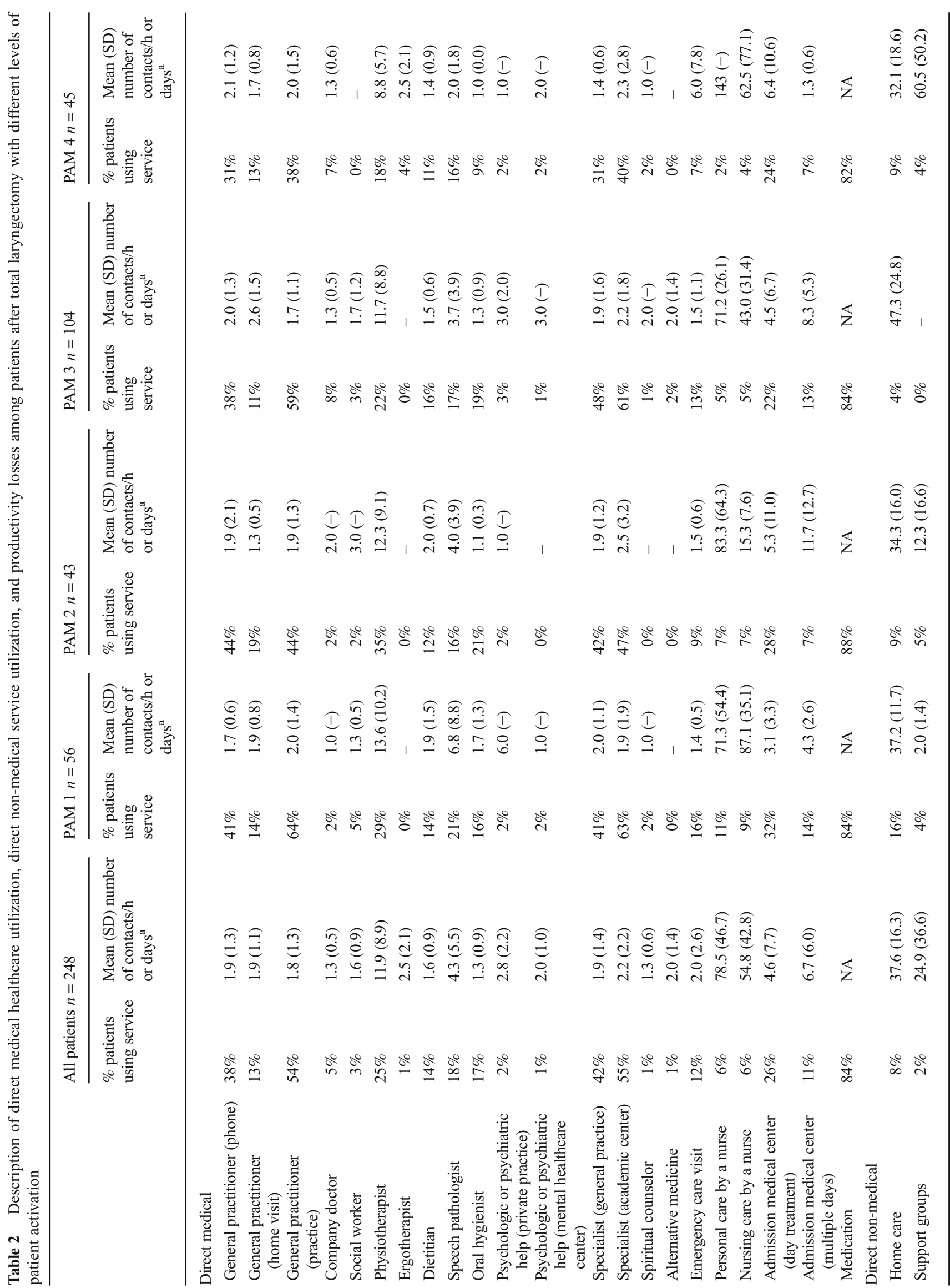




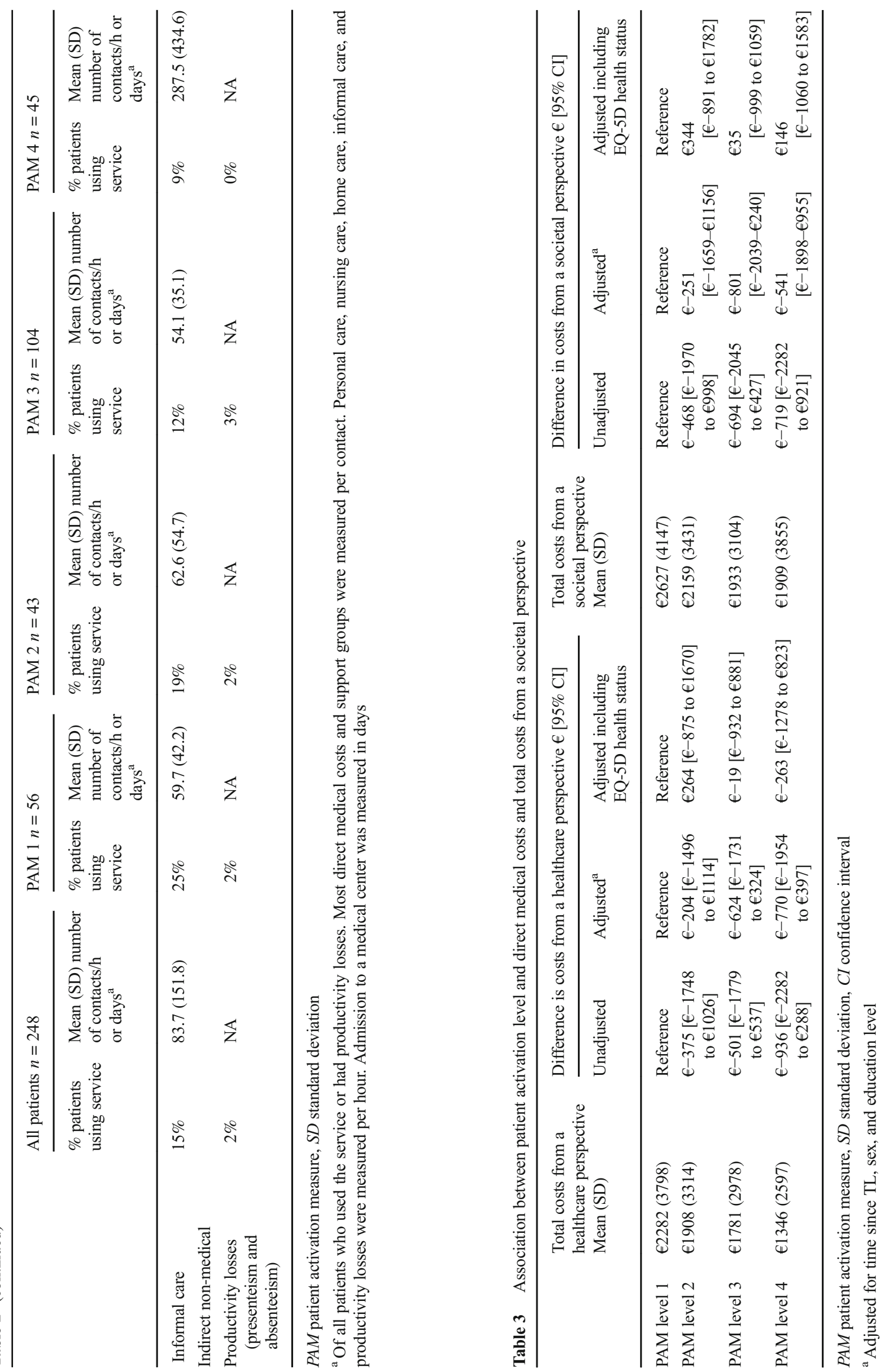


Table 4 Probability that costs are lower compared to the group with the lowest PAM score

\begin{tabular}{llll}
\hline & & $\begin{array}{l}\text { Total costs from a } \\
\text { healthcare perspective (\%) }\end{array}$ & $\begin{array}{l}\text { Total costs from a } \\
\text { societal perspective (\%) }\end{array}$ \\
\hline Unadjusted & PAM 2 vs. PAM 1 & 70 & 73 \\
& PAM 3 vs. PAM 1 & 80 & 87 \\
& PAM 4 vs. PAM 1 & 93 & 82 \\
Adjusted $^{\text {a }}$ & PAM 2 vs. PAM 1 & 62 & 63 \\
& PAM 3 vs. PAM 1 & 88 & 92 \\
Adjusted including EQ-5D $_{\text {health status }}$ & PAM 4 vs. PAM 1 & 91 & 79 \\
& PAM 2 vs. PAM 1 & 35 & 31 \\
& PAM 3 vs. PAM 1 & 52 & 48 \\
& PAM 4 vs. PAM 1 & 71 & 45 \\
\hline
\end{tabular}

PAM patient activation measure

The probability that total costs were lower in a certain PAM group compared to the first PAM group was investigated by replicating the regression analyses using bias-corrected accelerated bootstrapping with 5000 replications. The percentage described in this table presents the percentage of the 5000 bootstrap replications that showed lower total costs

${ }^{a}$ Adjusted for time since TL, sex, and education level
$5 \mathrm{D}$ health status, the probabilities were reduced to respectively 71 and $45 \%$ (PAM 4 vs. PAM 1), 52 and 48\% (PAM 3 vs. PAM 1), and 35 and $31 \%$ (PAM 2 vs. PAM 1). No statistically significant differences were found.

\section{Discussion}

This study aimed to investigate the associations between patient activation and total costs from a healthcare and societal perspective in cancer patients. To answer this research question, TL cancer patients were studied. We found that TL patients with a better patient activation reported less costs from a healthcare and societal perspective compared to patients with lower patient activation (probability of 70 to $93 \%$ ). This finding remained present when adjusting for sociodemographic and clinical characteristics (probability of 62 to $92 \%$ ).

Our findings on total costs from a healthcare perspective are in line with previous cross-sectional analyses of Hibbard et al. [26] and Greene et al. [18] conducted in primary care patients. Hibbard et al. [26] reported that the predicted total healthcare costs were $8 \%$ higher in the group with the lowest patient activation compared to the group with the highest patient activation, even when adjusted for several sociodemographic characteristics and a risk score for future costs. In the study of Greene et al. [18], predicted total healthcare costs were $8 \%$ higher in the lowest patient activation group and $12 \%$ higher in the second lowest group, compared to the highest patient activation group.

Besides healthcare costs, our study also included other important costs from a societal point of view, such as informal care costs and productivity losses. It was previously estimated that about $60 \%$ of the economic burden of cancer in the European Union is caused by productivity losses (including mortality and morbidity) and informal care costs [42], emphasizing the importance of conducting analyses from a societal perspective. In our study, we found that $15 \%$ of all TL patients received informal care, $8 \%$ received home care, $2 \%$ made use of support groups, and $2 \%$ (or $18 \%$ of all employed TL patients) had productivity losses. Of these cost categories, especially informal care usage seemed to decrease with better patient activation $(\mathrm{PAM} 1=25 \%$, PAM $2=19 \%$, PAM $3=12 \%$, and PAM $4=9 \%$ ). However, no clear influence of the inclusion of these costs on the association between patient activation and total costs was found; the adjusted probability to be less costly was $62-91 \%$ from a healthcare perspective compared to $63-92 \%$ from a societal perspective. Further research should look at the association between patient activation and different cost categories (e.g., healthcare costs, informal care costs, and productivity losses) in more detail.

As an additional analysis, we investigated the potential confounding role of EQ-5D health status on the association between patient activation and total costs from a healthcare and societal perspective. We found that after adjustment for EQ-5D health status, no association seemed to be present anymore (probability to be less costly was $31-71 \%$ ). Due to the cross-sectional design of the study, no conclusions can be drawn regarding causality of the association between health status, patient activation, and total costs. However, based on the conceptual framework of Howell et al. [7], it can be hypothesized that self-management interventions may improve patient activation, which in turn may improve patient health outcomes, such as health status and HRQOL, and reduce 
costs. So far, however, only a few randomized controlled trials have investigated the effectiveness of self-management interventions on patient activation, including one study in cancer patients [43], which showed inconclusive results [43-45]. Also, none of these studies investigated cost-effectiveness or cost-utility. One previous (non-randomized) prospective study in primary care patients, nevertheless, reported that primary care patients with a positive change in patient activation (e.g., from level 3 to 4 ) had lower total healthcare costs compared to patients who remained at PAM level 3 [18]. Further research should investigate whether patient activation can be improved in cancer patients, and whether this affects health status and total costs. A currently ongoing Dutch randomized controlled trial on the (cost-)effectiveness of a guided self-help program in TL cancer patients may provide further information regarding this association [10].

This study provides novel insights into the associations between patient activation and total costs, as no such study has previously been performed in cancer patients. Also, this is the first study that investigated the association between patient activation in relation to costs from a societal perspective. Some potential limitations, however, need also to be kept in mind. Firstly, information on healthcare utilization, service utilization, and productivity losses were obtained using self-report, which may have resulted in recall bias. Besides, missing data was not entirely missing at random; patients in the final study sample were significantly younger and had a significantly shorter time period since TL, which might influence representativeness of findings for the entire TL population. Representativeness of findings may also be influenced by the selection procedure. We decided to approach patients via the Dutch Patients' Association for Laryngectomees; as on average, only 150 patients are treated by TL each year in the Netherlands, and via the Patient Association, we were able to reach a large group of all TL patients. However, it can be hypothesized that activated patients are more likely to be a member of a patient association, which may have induced selection bias and, consequently, have influenced representativeness of findings. Finally, the relative low response of $32 \%$ may have influenced the representativeness of findings.

\section{Conclusion}

Patient activation is likely to be associated with total costs from both a healthcare and societal perspective in TL patients. TL patients with better patient activation reported less costs compared to patients with lower patient activation, even after adjusting for sociodemographic and clinical characteristics. However, after adjusting for EQ-5D health status, no such association seemed to be present anymore. More research on the causality of the association between patient activation, health status, and total costs from both a healthcare and a societal perspective in cancer patients is warranted.

Funding information The study was funded by the Michel Keijzer Fund, a fund from the Patients' Association for Laryngectomees.

Compliance with ethical standards The study was performed in accordance with the Dutch Medical Research Involving Human Subjects Act. Ethical approval was not necessary, as patients were not subjected to procedures or required to follow rules of behavior.

Conflict of interest The authors declare that they have no competing interests.

Open Access This article is distributed under the terms of the Creative Commons Attribution-NonCommercial 4.0 International License (http:// creativecommons.org/licenses/by-nc/4.0/), which permits any noncommercial use, distribution, and reproduction in any medium, provided you give appropriate credit to the original author(s) and the source, provide a link to the Creative Commons license, and indicate if changes were made.

\section{References}

1. Gee PM, Greenwood DA, Paterniti DA, Ward D, Miller LMS (2015) The eHealth enhanced chronic care model: a theory derivation approach. J Med Internet Res 17:e86

2. McCorkle R, Ercolano E, Lazenby M, Schulman-Green D, Schilling LS, Lorig K, Wagner EH (2011) Self-management: enabling and empowering patients living with cancer as a chronic illness. CA Cancer J Clin 61:50-62

3. Wagner EH, Austin BT, Davis C, Hindmarsh M, Schaefer J, Bonomi A (2001) Improving chronic illness care: translating evidence into action. Health Aff (Millwood ) 20:64-78

4. Neuhauser D (2003) The coming third health care revolution: personal empowerment Q manage. Health Care 12:171-184

5. Ventura F, Ohlen J, Koinberg I (2013) An integrative review of supportive e-health programs in cancer care. Eur J Oncol Nurs 17: 498-507

6. Slev VN, Mistiaen P, Pasman HR, Verdonck-de Leeuw IM, van Uden-Kraan CF, Francke AL (2016) Effects of eHealth for patients and informal caregivers confronted with cancer: a meta-review. Int $\mathrm{J}$ Med Inform 87:54-67

7. Howell D, Harth T, Brown J, Bennett C, Boyko S (2017) Selfmanagement education interventions for patients with cancer: a systematic review. Support Care Cancer 25:1323-1355

8. van den Berg SW, Gielissen MF, Ottevanger PB, Prins JB (2012) Rationale of the BREAst cancer e-healTH [BREATH] multicentre randomised controlled trial: an internet-based self-management intervention to foster adjustment after curative breast cancer by decreasing distress and increasing empowerment. BMC Cancer 12:394

9. van Helmondt SJ, van der Lee ML, de Vries J (2016) Study protocol of the CAREST-trial: a randomised controlled trial on the (cost-) effectiveness of a CBT-based online self-help training for fear of cancer recurrence in women with curatively treated breast cancer. BMC Cancer 16:527

10. Jansen F, Cnossen IC, Eerenstein SEJ, Coupé VMH, Witte BI, van Uden-Kraan CF, Doornaert P, Braunius WW, de Bree R, Hardillo JAU, Honings J, Halmos GB, Leemans CR, Verdonck-de Leeuw IM (2016) Effectiveness and cost-utility of a guided self-help 
exercise program for patients treated with total laryngectomy: protocol of a multi-center randomized controlled trial. BMC Cancer 16:580

11. Duman-Lubberding S, van Uden-Kraan CF, Jansen F, Witte BI, van der Velden LA, Lacko M, Cuijpers P, Leemans CR, Verdonck-de Leeuw IM (2016) Feasibility of an eHealth application "OncoKompas" to improve personalized survivorship cancer care. Support Care Cancer 24:2163-2171

12. Chatterton ML, Chambers S, Occhipinti S, Girgis A, Dunn J, Carter R, Shih S, Mihalopoulos C (2016) Economic evaluation of a psychological intervention for high distress cancer patients and carers: costs and quality-adjusted life years. Psychooncology 25:857-864

13. Krebber AM, Jansen F, Witte BI, Cuijpers P, de Bree R, BeckerCommissaris A, Smit EF, van Straten A, Eeckhout AM, Beekman AT, Leemans CR, Verdonck-de Leeuw IM (2016) Stepped care targeting psychological distress in head and neck cancer and lung cancer patients: a randomized, controlled trial. Ann Oncol 27:1754 1760

14. Bodenheimer T, Lorig K, Holman H, Grumbach K (2002) Patient self-management of chronic disease in primary care. JAMA 288: 2469-2475

15. Panagioti M, Richardson G, Small N, Murray E, Rogers A, Kennedy A, Newman S, Bower P (2014) Self-management support interventions to reduce health care utilisation without compromising outcomes: a systematic review and meta-analysis. BMC Health Serv Res 14:356

16. Jansen F, Krebber AM, Coupe VM, Cuijpers P, de Bree R, BeckerCommissaris A, Smit EF, van Straten A, Eeckhout GM, Beekman AT, Leemans CR, Verdonck-de Leeuw IM (2017) Cost-utility of stepped care targeting psychological distress in patients with head and neck or lung cancer. J Clin Oncol 35:314-324

17. Rademakers J, Nijman J, van der Hoek L, Heijmans M, Rijken M (2012) Measuring patient activation in The Netherlands: translation and validation of the American short form Patient Activation Measure (PAM13). BMC Public Health 12:577

18. Greene J, Hibbard JH, Sacks R, Overton V, Parrotta CD (2015) When patient activation levels change, health outcomes and costs change, too. Health Aff (Millwood ) 34:431-437

19. Hendriks M, Rademakers J (2014) Relationships between patient activation, disease-specific knowledge and health outcomes among people with diabetes; a survey study. BMC Health Serv Res 14:393

20. Remmers C, Hibbard J, Mosen DM, Wagenfield M, Hoye RE, Jones C (2009) Is patient activation associated with future health outcomes and healthcare utilization among patients with diabetes? J Ambulatory Care Manage 32:320-327

21. Rask KJ, Ziemer DC, Kohler SA, Hawley JN, Arinde FJ, Barnes CS (2009) Patient activation is associated with healthy behaviors and ease in managing diabetes in an indigent population. Diabetes Educator 35:622-630

22. Greene J, Hibbard JH (2011) Why does patient activation matter? An examination of the relationships between patient activation and health-related outcomes. J Gen Intern Med 27:520-526

23. Begum N, Donald M, Ozolins IZ, Dower J (2011) Hospital admissions, emergency department utilisation and patient activation for self-management among people with diabetes. Diabetes Res Clin Pract 93:260-267

24. Mitchell SE, Gardiner PM, Sadikova E, Martin JM, Jack BW, Hibbard JH, Paasche-Orlow MK (2013) Patient activation and 30-day post-discharge hospital utilization. J Gen Intern Med 29: 349-355

25. Kinney RL, Lemon SC, Person SD, Pagoto SL, Saczynski JS (2015) The association between patient activation and medication adherence, hospitalization, and emergency room utilization in patients with chronic illnesses: a systematic review. Patient Educ Couns 98:545-552

26. Hibbard JH, Greene J, Overton V (2013) Patients with lower activation associated with higher costs; delivery systems should know their patients' 'scores'. Health Aff (Millwood) 32:216-222

27. Burnip E, Owen SJ, Barker S, Patterson JM (2013) Swallowing outcomes following surgical and non-surgical treatment for advanced laryngeal cancer. J Laryngol Otol 127:1116-1121

28. Perry A, Casey E, Cotton S (2015) Quality of life after total laryngectomy: functioning, psychological well-being and self-efficacy. Int J Lang Commun Disord 50:467-475

29. Singer S, Danker H, Guntinas-Lichius O, Oeken J, Pabst F, Schock J, Vogel HJ, Meister EF, Wulke C, Dietz A (2014) Quality of life before and after total laryngectomy: results of a multicenter prospective cohort study. Head Neck:359-368

30. Szuecs M, Kuhnt T, Punke C, Witt G, Klautke G, Kramp B, Hildebrandt G (2015) Subjective voice quality, communicative ability and swallowing after definitive radio(chemo)therapy, laryngectomy plus radio(chemo)therapy, or organ conservation surgery plus radio(chemo)therapy for laryngeal and hypopharyngeal cancer. J Radiat Res 56:168

31. Moukarbel RV, Fung K, Franklin JH, Leung A, Rastogi R, Anderson CM, Yoo JH (2010) Neck and shoulder disability following reconstruction with the pectoralis major pedicled flap. Laryngoscope 120:1129-1134

32. Gourin CG, Dy SM, Herbert RJ, Blackford AL, Quon H, Forastiere AA, Eisele DW, Frick KD (2014) Treatment, survival, and costs of laryngeal cancer care in the elderly. Laryngoscope 124:1827-1835

33. Cohen SM, Kim J, Roy N, Asche C, Courey M (2012) The impact of laryngeal disorders on work-related dysfunction. Laryngoscope 122:1589-1594

34. Bouwmans C, Hakkaart-van Rooijen L, Koopmanschap M, Krol M, Severens H, Brouwer W (2013) Handleiding iMTA Medical Consumption Questionnaire. In: Editor (ed)^(eds) Book Handleiding iMTA Medical Consumption Questionnaire

35. Bouwmans C, Hakkaart-van Roijen L, Koopmanschap M, Krol M, Severens H, Brouwer W (2013) Handleiding iMTA Productivity Costs Questionnaire. In: Editor (ed)^(eds) Book Handleiding iMTA Productivity Costs Questionnaire

36. Hakkaart-van Rooijen L, Tan SS, Bouwmans CAM (2010) Handleiding voor kostenonderzoek Methoden en standaard kostprijzen voor economische evaluaties in de gezondheidszorg. In: Editor (ed)^(eds) Book Handleiding voor kostenonderzoek Methoden en standaard kostprijzen voor economische evaluaties in de gezondheidszorg

37. Hibbard JH, Stockard J, Mahoney ER, Tusler M (2004) Development of the Patient Activation Measure (PAM): conceptualizing and measuring activation in patients and consumers. Health Serv Res 39:1005-1026

38. Brooks R (1996) EuroQol: the current state of play. Health Policy 37:53-72

39. Lamers LM, Stalmeier PFM, McDonnell J, Krabbe PFM, van Busschbach JJ (2005) Measuring the quality of life in economic evaluations: the Dutch EQ-5D tariff. Ned Tijdschr Geneeskd 149: $1574-1578$

40. Magnezi R, Glasser S, Shalev H, Sheiber A, Reuveni H (2014) Patient activation, depression and quality of life. Patient Educ Couns 94:432-437

41. Elliott R, Payne K (2004) Statistical handling of data in economic analysis Essentials of Economic Evaluation in Healthcare. Pharmaceutical Press

42. Luengo-Fernandez R, Leal J, Gray A, Sullivan R (2013) Economic burden of cancer across the European Union: a population-based cost analysis. Lancet Oncol 14:1165-1174

43. Kvale EA, Huang CS, Meneses KM, Demark-Wahnefried W, Bae S, Azuero CB, Rocque GB, Bevis KS, Ritchie CS (2016) Patient- 
centered support in the survivorship care transition: outcomes from the patient-owned survivorship care plan intervention. Cancer 122: $3232-3242$

44. Lara-Cabrera ML, Salvesen O, Nesset MB, De las Cuevas C, Iversen VC, Grawe RW (2016) The effect of a brief educational programme added to mental health treatment to improve patient activation: a randomized controlled trial in community mental health centres. Patient Educ Couns 99:760-768
45. McCusker J, Lambert SD, Cole MG, Ciampi A, Strumpf E, Freeman EE, Belzile E (2016) Activation and self-efficacy in a randomized trial of a depression self-care intervention. Health Educ Behav 43:716-725 